\title{
Molecular Specificity of Defined Types of Amacrine Synapse in Cat Retina
}

\author{
Peter Sterling and Lois A. Lampson \\ Department of Anatomy, University of Pennsylvania, Philadelphia, Pennsylvania 19104
}

\begin{abstract}
The inner plexiform layer of cat retina contains synaptic structures belonging to 50 or more types of "identified" neurons. To learn whether there are antigens confined to subsets of these synaptic structures, we raised monoclonal antibodies to homogenates of neural retina. Binding patterns of these antibodies were visualized by the peroxidase-antiperoxidase method and studied in serial, ultrathin sections by electron microscopy. Four antibodies stained the synaptic varicosities of certain amacrine cells. Many of the stained varicosities formed reciprocal synapses with a rod bipolar axon terminal, but only about half of the reciprocal synapses associated with a rod bipolar were stained. Other stained varicosities formed synapses with cone bipolar axons, ganglion cell dendrites, and unstained amacrine processes. The patterns were essentially the same for each antibody and were not altered by staining with the antibodies two at a time; therefore, it is likely that all four antibodies stain the same subset of synaptic structures. These patterns would be accounted for if there were staining of all the synaptic varicosities of three of the four types of identified amacrine reciprocally connected to the rod bipolar (A6, A8, A13). This localization suggests that the antigen responsible for the binding pattern is not associated with synaptic transmission. Staining is present in the inner plexiform layer during the period of synaptogenesis and consequently the antibodies are serving as markers for following the development of identified synapses in an identified neural circuit.
\end{abstract}

Molecular specificity in nervous tissue can now be defined by means of monoclonal antibody and nucleic acid probes (Abelson and Butz, 1984; Cold Spring Harbor Symposium, 1983; Lampson, 1984). Much of the specificity defined so far has been at the level of neuronal subpopulations. For example, certain monoclonal antibodies mark specific sets of "identified" neurons in invertebrates such as leech (McKay et al., 1984; Zipser and McKay, 1981), Drosophila (Fujita et al., 1982; Zipursky et al., 1985), and nematode (Okamoto and Thomson, 1985). There are also monoclonal antibodies that mark subpopulations of neurons in the vertebrate CNS, including cerebellum (Hawkes et al., 1982; Sternberger, 1982), spinal cord (McKay and Hockfield, 1982), and retina (Barnstable, 1980; Drager et al, 1984; Lemmon and Gotllieb, 1982; Young and Dowling, 1984).

One goal for which it has been widely hoped that the hybridoma technology would prove useful is the identification of antigens at the synaptic junctions between specific types of neuron.

\footnotetext{
Received June 24, 1985; revised Oct. 7, 1985; accepted Oct. 22, 1985.

We thank Cheryl A. Fisher for assistance in the production and radioimmunoassay of the antibodies, Miriam Kirschner for assistance in the peroxidaseantiperoxidase microscopic assays, John R. Megill for working out the electron microscopic assays and preparing the illustrations, and April Firstencel for performing the reconstructions. We are grateful to Harriet $\mathrm{B}$. Abriss for typing the manuscript. This work was supported by NINCDS Grant NS16552 and NSF Grant PCM79 26757 (L.A.L.) and NIH Grants EY00828 and EY01583 (P.S.). This work has been reported briefly elsewhere (Sterling and Lampson, 1983).
} Copyright (C) 1986 Society for Neuroscience $0270-6474 / 86 / 051314-11 \$ 02.00 / 0$
An antigen with such a narrow localization might be important in establishing or maintaining the specificity of that connection. Furthermore, the very probe that identified such an antigen might also be the tool with which to block its function and so experimentally alter the connection. Such probes would also be useful markers for following the detailed morphological development of specific connections. So far, however, no antigen has been shown to be restricted to the pre- or postsynaptic structures of a specific neural circuit.

Antigens have been localized to pre- or postsynaptic structures of defined cell types, but these are all molecules apparently involved in synaptic transmission or modulation. Examples are neuropeptides (e.g., Brecha, 1983), neural transmitter enzymes (e.g., Oertel et al., 1983), and phosphoproteins (e.g., De Camilli et al., 1983; Ouimet et al., 1984). The physiological functions of such molecules at the synapse, being rather general, are often shared by several different cell types in a given tissue and therefore are not restricted to a particular type of synapse. For example, the GABA-synthetic enzyme, glutamic acid decarboxylase (GAD), is present in the presynaptic terminals of four different neuron types in cerebellar cortex (McLaughlin et al., 1974). It is therefore not a unique marker for the individual connections of any one of those types. This broader distribution of GAD does not logically exclude it from a role in establishing connections. On the other hand, there may well be synaptic antigens with a still narrower localization.

In order to detect an antigen restricted to a specific type of synapse, one requires a tissue in which various subsets of synapses have already been identified. Antibodies raised to extracts of the tissue may be screened initially in the LM for staining of punctate structures in the neuropil. The final screening, however, must be carried out at the EM level in order to identify the stained synaptic structures. Furthermore, since specific synapses even in a well-characterized neuropil can rarely be identified with certainty in a single, ultrathin section, serial sections must be cut from immunostained tissue in order to establish the identity of the stained elements.

The cat retina seemed a promising tissue for this purpose because, among the complex neuropils of the vertebrate CNS, it is the best understood in terms of specific circuitry. The inner plexiform layer contains the processes of more than 50 types of neuron (23 ganglion, 22 amacrine, 10 bipolar, 2 interplexiform) intertwined so that all types are within microns of each other (Kolb et al., 1981; McGuire et al., 1984; Sterling, 1983). The circuits interconnecting these neurons are extremely specific, the processes of each type having direct synaptic connections with only a small subset of the others. Many of the connections, furthermore, have been "identified" in the same sense as for the neurons in the ganglia of invertebrates (Freed and Sterling, 1985; Kolb and Nelson, 1984; McGuire et al., 1986; Sterling, 1983). We therefore raised monoclonal antibodies to homogenates of cat retina and screened them first in the LM and then in the EM. Evidence is reported here for an antigen localized to the synaptic varicosity of a small subset of amacrine types. 


\section{Materials and Methods}

\section{Immunization}

One of our original goals was to raise antibodies to specific regions of the adult retina: right and left temporal, and right and left nasal. Our strategy employed hyperimmune serum in an effort to direct the immune response away from unwanted determinants. This strategy had been used in previous fusions in other laboratories in which cell-type-specific monoclonals had been obtained (Horwitz et al., 1984; Kennett and Gilbert, 1979). Freshly dissected adult cat retinas were divided along the vertical meridian, giving temporal and nasal pieces that were kept separate for the left and right eyes. Each piece was gently homogenized in cold PBS with a ground glass pestle and used to raise a hyperimmune mouse serum. The sera were evaluated by radioimmunoassay against glutaraldehyde-fixed tissue homogenates. Each serum showed strong binding to cat tissue, including brain, retina (all four regions), and nonneural tissues.

\section{Hybridoma production}

Homogenized retina from the right nasal region was mixed with hyperimmune serum to the left temporal homogenate. This was injected intraperitoneally in complete Freund's adjuvant into two mice to be used for fusion. One month later, the mice were boosted with the same mixture, in PBS, delivered intraperitoneally. Two months after the boost, a final immunization with the same mixture was delivered intravenously. Four days later, the spleens were fused individually to P3X63Ag8.653 cells, as described previously (Lampson and Levy, 1980). Eleven vigorously growing colonies were obtained from fusion $A$ and 10 from fusion D. In each case, this represented less than $10 \%$ of the wells plated.

The culture supernatants were screened by the peroxidase-antiperoxidase (PAP) technique, as described below, and by radioimmunoassay (RIA). The RIA was performed in microtiter plates as described previously (Lampson and Levy, 1980). Retina homogenates that had been fixed in $0.1 \%$ glutaraldehyde for $5 \mathrm{~min}$ at room temperature were used as targets (Lampson and Levy, 1980).

\section{Immunocytochemistry}

\section{Light microscopy}

Retina was obtained from adult cats deeply anesthetized with sodium pentobarbital and perfused with $2 \%$ glutaraldehyde- $2 \%$ paraformalde-

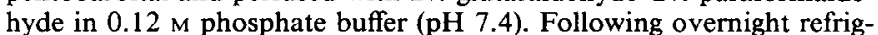
eration of the eye, pieces of the retina were dissected, embedded in albumin, and sectioned radially at $50 \mu \mathrm{m}$ on a vibratome. Antibody was applied at a dilution of $1 / 20$ for $48 \mathrm{hr}$ at $4^{\circ} \mathrm{C}$ and an additional 12 $\mathrm{hr}$ at room temperature. Its binding was visualized as a diaminobenzidine (DAB) reaction product by means of the PAP technique (Lampson et al., 1984; Sternberger, 1979). The sections were mounted in glycerin, coverslipped, and examined with Nomarski optics.

This standard procedure was varied in several ways.. We tried other fixatives, such as $3 \%$ paraformaldehyde- $1 \%$ glutaraldehyde, and $4 \%$ paraformaldehyde $-0.1 \%$ glutaraldehyde. We also tried the postfixation procedures recommended by Eldred et al. (1983), which involves overnight soaking in $4 \%$ paraformaldehyde in borate buffer, $\mathrm{pH} 10$, followed by $1 \%$ sodium borohydride ( $30 \mathrm{~min}$, ph 7.4 ). The antibody concentration was also varied (from $1 / 4$ to $1 / 100$ ). Finally, we also visualized the antibodies by means of the avidin-biotin complex. No important differences were observed between the various fixation and postfixation procedures with respect to either the intensity or the distribution of staining. The dilutions and the method of visualization affected the intensity of the stain, but not its distribution pattern. Under the conditions described, the PAP method provided stronger staining than the avidin-biotin method.

\section{Electron microscopy}

The immunostained sections were osmicated $(2 \%, 60 \mathrm{~min})$, stained in uranyl acetate in maleate buffer $(0.5 \%, 90 \mathrm{~min})$, dehydrated in methanol, and embedded in Epon. Ultrathin sections were collected on Formvarcoated slot grids, stained further with $0.1 \%$ lead citrate $(1 \mathrm{~min})$ and methanolic uranyl acetate $(4 \%, 30 \mathrm{~min})$, and examined in the EM. We determined that stain penetrated the tissue to a depth of about $5 \mu \mathrm{m}$ from either surface. Thus, the zone in which the binding patterns might be observed was rather narrow. We therefore adopted the practice of collecting in series every thin section (about 50) from the surface of the tissues to the depth where the stain faded. The corresponding regions of each section were then photographed in the EM.

\section{Results}

\section{Initial screening of the hybridomas}

The supernatants of the 21 vigorously growing colonies were screened by two independent assays. These were RIA against fixed retina homogenates and the PAP assay against retina sections.

In RIA, 10 culture supernatants ( 5 from each fusion) were positive against retina. We did not observe consistent differences in binding to homogenates from the four different regions (right temporal, etc.). In the PAP assay, 13 supernatants were positive. These included all of those that were positive in RIA, and 3 additional supernatants from fusion $A$ that were negative in RIA. When the staining patterns to sections from the different regions were compared, there were no consistent region-specific differences. Indeed, RIA against additional tissue homogenates showed the antibodies to react with other neural tissues and also non-neural tissues, with different antibodies showing different patterns of reactivity against the panel (Lampson and Sterling, unpublished observations). Thus, as others have observed (Horwitz et al., 1984; Kennett et al., 1978), the fusion protocol did lead to a limited number of positive clones. In this case, the sample size may have been too small to reveal the regional specificity originally sought, or the antibody repertoire may have been skewed in an unanticipated direction. The important point here is that the microscopic assays did reveal antibody specificity within the retina, as described below. Of the four antibodies to be described in detail, A257, A282, and A359 came from one fusion, and D334 from the second fusion. A257 is a $\gamma 2 \mathrm{a}$ immunoglobulin, and the other three antibodies are IgMs. A257 was active in the PAP assay, but not in RIA; the other three antibodies were active in both assays.

\section{Light microscopy of immunostained retina}

\section{General pattern shared}

All 13 of the antibodies that were positive in the PAP assay stained neurons, and none stained Muller cells or glia. We selected for detailed study four antibodies that had in common a strong staining of the inner plexiform layer (Fig. 1, $A-D$ ). The staining patterns of these four antibodies for the rest of the neural retina were also generally similar. Thus, all four left the photoreceptors unstained, except for some patchiness around certain somas in the outer nuclear layer. The outer plexiform layer was also unstained except for some extremely fine, beaded processes, probably belonging to the interplexiform cell and the coarse dendrites of certain cone bipolars. In the inner nuclear layer, neither horizontal cells nor rod bipolars were stained.

There was strong staining by all four antibodies of the somas of certain cone bipolars and of most amacrine and ganglion cells. The cone bipolars stained by a given antibody resembled each other morphologically as though they might belong to a particular type. For example, the cone bipolars stained by antibody D334 all had somas flattened against the horizontal cell layer and had a fairly regular spacing (Fig. 1A). The minor differences noted between antibodies in cell-staining patterns werc that antibodics A282 and A359 stained fewer amacrine somas than D334, while A359 stained fewer ganglion cells. A257 stained the somas of all ganglion and amacrine cells and of many cone bipolar cells. A257 also stained neuronal nuclei while the other antibodies did not. 


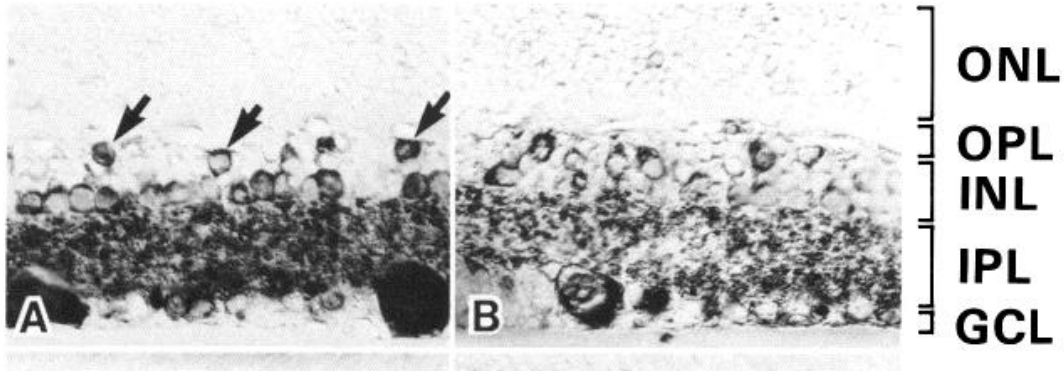

Figure 1. Staining patterns of four different monoclonal antibodies raised against cat retina. $A$, Antibody D334; $B$, A 359; $C, \mathrm{~A} 282 ; D, \mathrm{~A} 257$. Stain is absent from photoreceptors, horizontal cells, and outer plexiform layers. Stain is present in somas of certain cone bipolar, amacrine, and ganglion cell bodies but largely absent from their arborizations in the inner plexiform layer $(I P L)$. Stain in the IPL is confined to small, spheroidal structures (seen best in Fig. 2). Arrows in $A$ point to subset of stained cone bipolars with similar position and morphology; arrow in $D$ marks stained alpha ganglion cell dendrite. Abbreviations: $O N L$, outer nuclear layer; $O P L$, outer plexiform layer; $I N L$, inner nuclear layer; $G C L$, ganglion cell layer.

\section{Inner plexiform layer}

There were two striking features to the staining patterns of these antibodies in the inner plexiform layer. First, stain was absent in the axonal and dendritic arborizations of the cone bipolar, amacrine, and ganglion cells despite the strong staining of their somas in the cellular layers. The sharp exclusion of stain from the dendrites of an alpha ganglion cell is shown in Figure 2 (antibody D334), and a similar restriction of stain from a cone bipolar axon is illustrated in the electron micrograph of Figure 5. The only exception to this rule was that antibody A257 strongly stained the lower-order dendrites of alpha and beta ganglion cells (Fig. 4). This antibody resembled the other three, however,

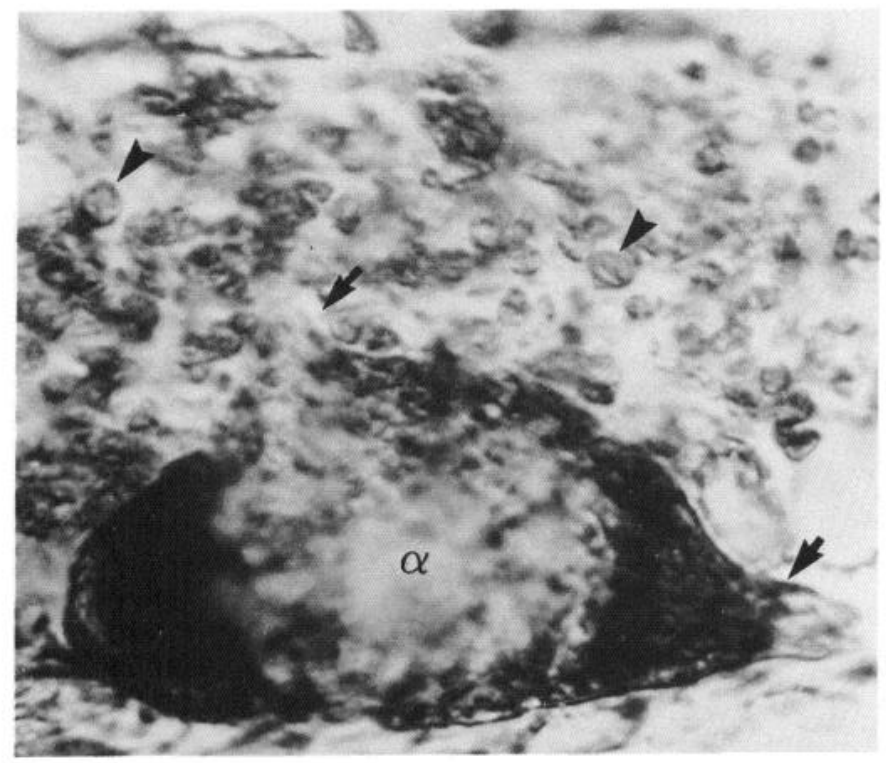

$10 \mu \mathrm{m}$

Figure 2. Antibody D334. Spheroidal structures stained in IPL (arrowheads). Note stained soma of $\mathrm{ON}$-alpha ganglion cell, and absence of stain beyond base of proximal dendrites (arrows). in failing to stain the arborizations of bipolar and amacrine cells in the inner plexiform layer.

The other striking feature shared by all four antibodies was that the structures stained in the inner plexiform layer were primarily small, spheroidal granules, $0.5-1.5 \mu \mathrm{m}$ in diameter (Figs. 2-4). These were distributed densely but evenly throughout the full depth of the layer and were apparently unconnected to each other or to any other structure. To learn the identity of these structures, we examined them in the EM.

\section{Electron microscopy of the inner plexiform layer}

\section{Amacrine synapses stained}

The spheroidal structures stained by all four antibodies were observed in the EM to be the varicosities of amacrine processes (Figs. 5-7). These contained synaptic vesicles and exchanged synapses with other processes in the surrounding neuropil. Amacrine varicosities are known to be interconnected by fine cytoplasmic strands (Cajal, 1892), and it was striking that these failed to stain. Figure 6 shows several examples of stained varicosities in continuity with their unstained cytoplasmic strands. This explained why the stained spheroidal structures appear in the LM to be unconnected. The absence of stain from these connecting strands was probably not an artifactual failure of the stain to penetrate processes of fine caliber because equally fine processes were stained in the outer plexiform layer (see above). Apparently, therefore, the determinants that bind these antibodies in the inner plexiform layer are almost entirely restricted to amacrine synapses.

In these synapses stain accumulated in the cytoplasm, often obscuring the synaptic vesicles. Usually there was also a darkening of the plasma membrane as compared to the membranes of adjacent unstained processes (Figs. 6, 9-11). The reaction product of the PAP assay is too diffuse and sticky, however, to be certain of the actual subcellular localization of the antigen. This awaits study with a higher resolution label, such as gold.

\section{Stained synapses associated with rod bipolar axon}

We wished to learn whether the binding was to all amacrine synapses or to a particular subset. Twenty-two forms of amacrine have been distinguished in cat retina by their different patterns of arborization (Kolb et al., 1981). However, we could 


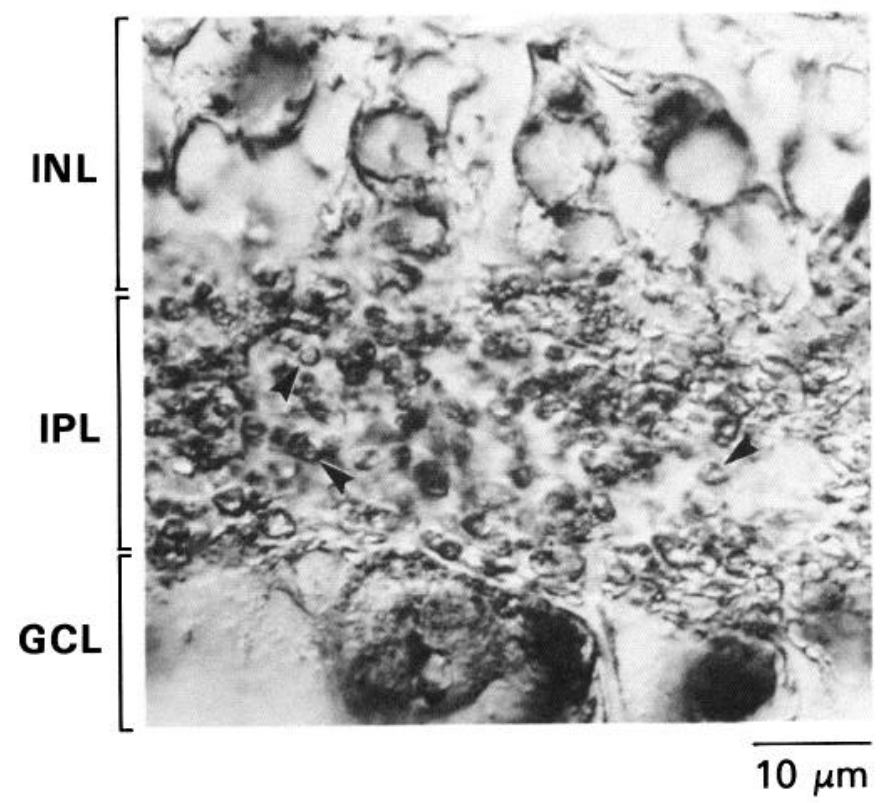

Figure 3. Antibody A359. Spheroidal structures stained in IPL (arrowheads). Stain is absent from bipolar axons and ganglion cell dendrites. Abbreviations as in Fig. 1.

not directly relate the stained synapses to this classification scheme because the arborizations, of which each varicosity formed a miniscule part, could not be traced. We therefore sought to determine the synaptic relationships of the stained varicosities in order to match them with amacrine types whose synaptic relationships are known. The primary effort focused on sublamina $b$ of the inner plexiform layer because that is where the synaptic relationships are best understood (Kolb and Nelson, 1984; McGuire et al., 1984; Sterling, 1983).

In single sections through sublamina $b$, stained profiles were often clustered along the vertically oriented axon terminal of the rod bipolar (Fig. 7). This relationship was investigated by partially reconstructing 16 rod bipolar axons from immunostained tissue along with their immediately surrounding processes. It can be seen in Figure 8, which shows three of these reconstructions, that the rod bipolar axon is studded with stained amacrine varicosities. It can also be seen that not every varicosity associated with the axon is stained and that the proportion of stained to unstained varicosities is different for the three axons. Thus, for one rod bipolar about $50 \%$ of the surrounding varicosities were stained, while for another about $80 \%$ were stained. Although the illustration represents staining by three different antibodies, a similar variation in the proportion of stained to unstained varicosities was observed for each individual antibody.

The synaptic relationships between the rod bipolar and the stained varicosities were examined next. Each site of the rod bipolar's synaptic output is marked by a small, electron-dense "ribbon." Postsynaptic at each ribbon (Fig. 9) there are two processes called a "dyad" by Dowling and Boycott (1966). Each rod bipolar has about 30 ribbons and, therefore, about 30 dyads (McGuire et al., 1984). One member of the dyad is purely postsynaptic and belongs to the type AII amacrine cell (Famiglietti and Kolb, 1975). The other member of the dyad contains clusters of synaptic vesicles and invariably returns a synaptic contact to the rod bipolar (McGuire et al., 1984). This element of the dyad is consequently referred to as a "reciprocal" amacrine. Other amacrine varicosities are presynaptic but not postsynaptic to the rod bipolar axon terminal and are called nonreciprocal (McGuire et al., 1984).

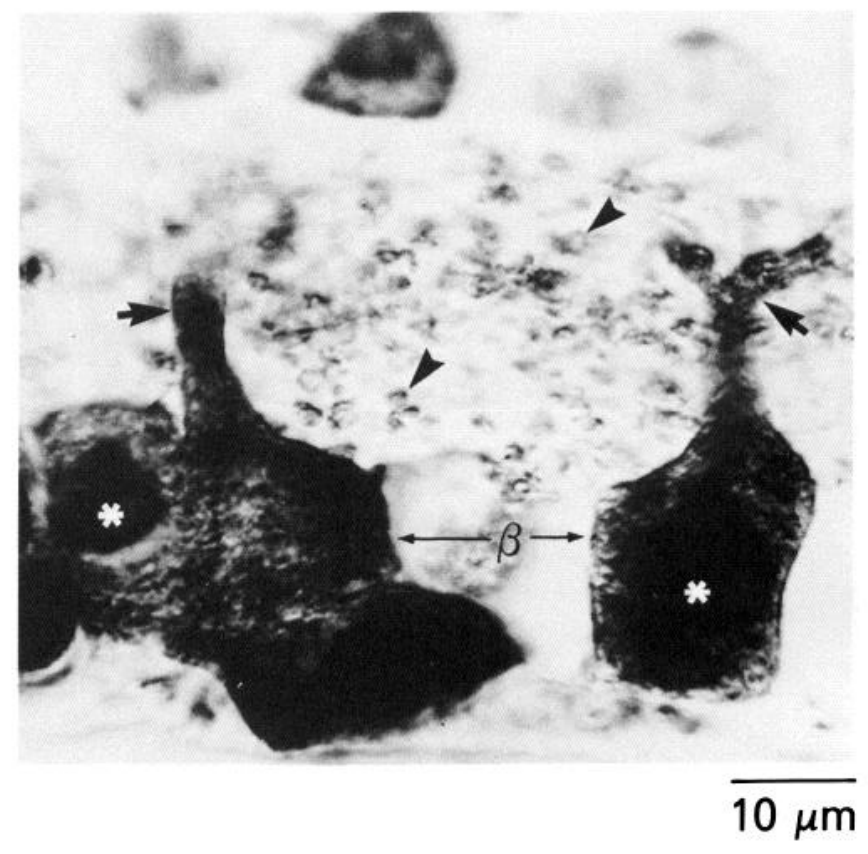

Figure 4. Antibody A257. Stained spheroidal structures in IPL (arrowheads). Note, in contrast to Figures 2 and 3, the strong staining of ganglion cell nuclei (asterisk) and dendritic cytoplasm (arrows). $\beta$, OFFbeta ganglion cells.

The reconstructions allowed us to examine 5-11 dyads postsynaptic to individual rod bipolars. We observed that the process belonging to the AII amacrine was never stained. Frequently, however, the process belonging to the reciprocal amacrine varicosity was stained (Fig. 9). For an individual rod bipolar the proportion of dyads with one stained element varied in our reconstruction from 90 to $13 \%$. Possibly this represents actual biological variation in the synaptic connections of stained varicosities with individual rod bipolars. This is not certain, however, because the 5-11 ribbons recovered in an individual rod bipolar represent no more than one-third of its full complement (McGuire et al., 1984). Therefore, the sample of dyads postsynaptic to an individual rod bipolar axon was too small to reasonably estimate the true proportion that contain a stained process.

\section{All antibodies stain the same reciprocal synapses}

We asked whether all four antibodies stain the same or different proportions of the reciprocal amacrine varicosities at the dyad. For each antibody we pooled the dyads identified by reconstruction along with all the dyads that we could identify in serial sections of the neuropil. The proportion of dyads with a stained varicosity was $50.3 \%$ (129 dyads counted) for antibody D334, $45 \%$ (124) for A282, $40 \%$ (57) for A257, and 36\% (87) for A 359 . We believe that the low proportion of dyads stained by antibody A359 may have resulted from the relatively poor penetration of this antibody. Thus, all four antibodies appear to stain a similar proportion of reciprocal varicosities at the rod bipolar dyad.

To determine whether all of the antibodies stain the same subset of the reciprocal varicosities, tissue was incubated with two antibodies at a time. The tissue was then examined to see whether the proportion of stained to unstained varicosities reciprocal to the rod bipolar was altered. The answer was clearcut: No combination of antibodies increased the proportion of stained reciprocal varicosities above the $36-50 \%$ stained by each antibody individually. 


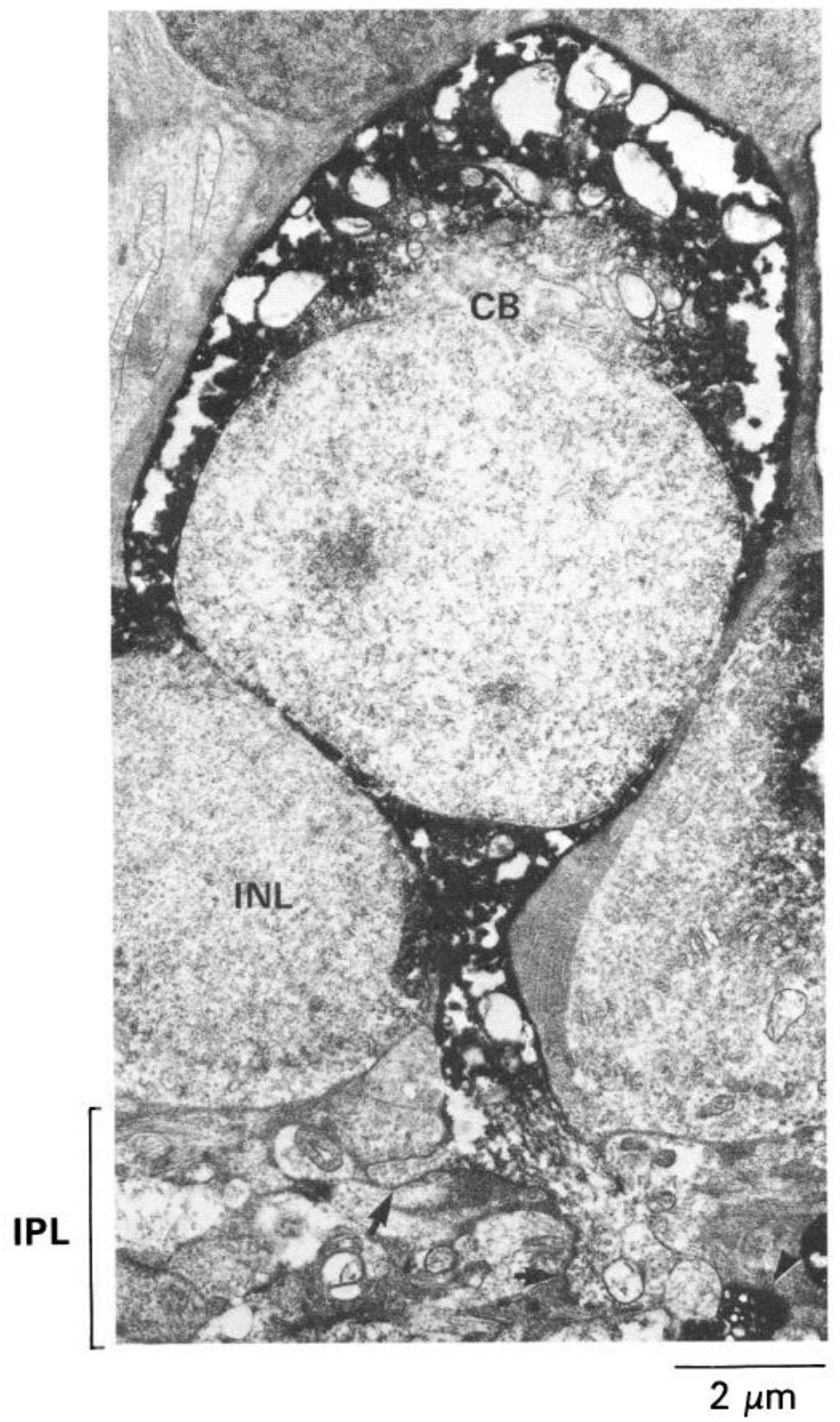

Figure 5. Antibody D334. Electron micrograph of stained cone bipolar with axon arborizing in sublamina $a$ of IPL. Note absence of stain in the axon beyond its entry into the IPL (arrows), arrowhead, stained varicosity.

The nonreciprocal amacrine varicosities with input to the rod bipolar were not observed to be stained. There remains some uncertainty here, however, because dense stain often obscured synaptic vesicles, and it is possible for some stained nonreciprocal varicosities to have gone unnoticed. This was not a problem with the reciprocal varicosities because they were always identified by their stereotyped location postsynaptic to the rod bipolar ribbon. We conclude, with the foregoing reservation, that the only structure synapsing with the rod bipolar axon that is stained by these antibodies is the reciprocal amacrine varicosity. Further, only about half of these are stained.

\section{Stained synapses associated with other structures}

Stained amacrine varicosities were synaptically associated with certain other structures in sublamina $b$. They were postsynaptic to other amacrines, and in several cases they were observed postsynaptic to a ribbon contact from the type $\mathrm{CBb}_{1}$ cone bipolar (Fig. 10). This bipolar was itself identified by its pale cytoplasm and gap junctions with the AII (McGuire et al., 1984). Stained varicosities were also associated in sublamina $b$ with certain
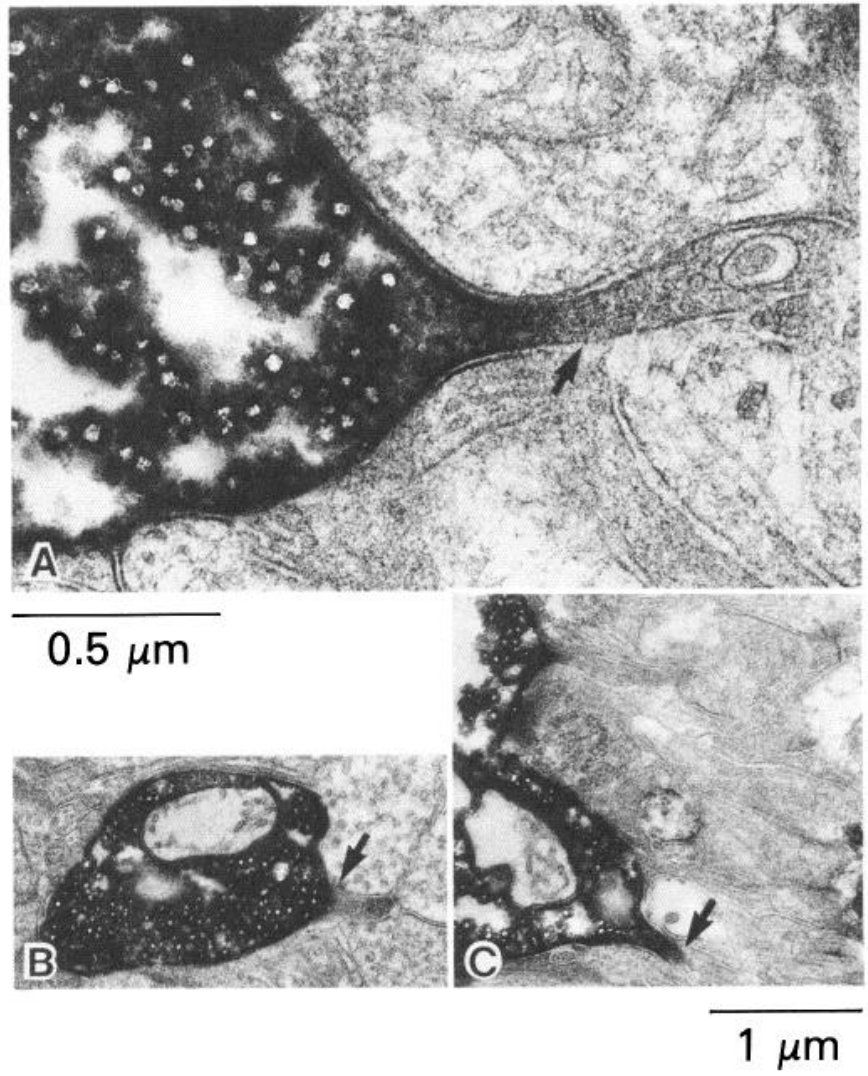

Figure 6. $A$ and $B$, Antibody A282; $C$, antibody D334. Amacrine varicosities are stained, but stain fades at the neck and is absent from nonsynaptic interconnecting processes.

ganglion cell dendrites. These were large-caliber dendrites, containing pale cytoplasm and numerous microtubules, which identified them as the proximal dendrites of the $\mathrm{ON}$-alpha ganglion cell (Stevens et al., 1980).

Where a stained varicosity made synaptic contact onto the ON-alpha dendrite, there was a curious staining by three of the antibodies (D334, A282, A359) of the postsynaptic cell (Fig. 11). Staining was observed both in the postsynaptic membrane and also in the adjacent cytoplasm. This punctate staining of the $\mathrm{ON}$-alpha dendrite was repeated at several points along its length, always in postsynaptic relationship to a stained varicosity. In sublamina $a$ there was a similar punctate staining along the large dendrites of the OFF-alpha cells, again in postsynaptic association to stained varicosities. In these cases, as well, there was staining of the postsynaptic membrane and cytoplasm. This feature was observed in several retinas with each of the three antibodies and at all dilutions of the antibody that stained the amacrine varicosities. The other synaptic connections of the stained varicosities in sublamina $a$ were not studied.

Finally, in qualitative observations of the tissue stained with two antibodies at a time, we failed to find additional synaptic structures of any kind stained by a combination of the antibodies that were not stained by the four individual antibodies. Thus, all of our observations suggest that the synaptic structures stained by all four antibodies are the same.

\section{Discussion}

\section{Staining patterns reproducible}

The staining patterns described here were the same under different conditions of fixation (with or without glutaraldehyde), with different reagents bearing the HRP molecule (PAP, ABC), 
and over a range of antibody dilutions (1/4-1/100). These staining patterns could not have resulted from differential penetration of stain. The best evidence for this came from tracing stained and unstained processes in serial sections toward the tissue surface. We could usually observe the stain to intensify in the one process and not to appear in the other. Furthermore, the unstained process was sometimes cut open at the tissue surface while the stained process was not. Penetration of the cut process was thereby favored; nevertheless, it remained unstained. We conclude, therefore, that the staining patterns represent genuine differences in binding rather than differential penetration of the staining reagents.

\section{Staining patterns shared}

The overall staining patterns with the four antibodies studied were broadly similar. Thus, all four failed to stain outer retina and horizontal and rod bipolar cells. All of the four stained strongly certain cone bipolar, amacrine, and ganglion cell bodies, and the amacrine synapses in the inner plexiform layer. The staining differences between antibodies in the LM were mostly subtle; for example, there were differences in the proportion of bipolar, amacrine and ganglion cell somas stained. The single outstanding difference was that A257, but not the others, stained neuronal nuclei and the lower-order dendritic arborizations of alpha and beta ganglion cells.

The staining of amacrine synapses in the inner plexiform layer by all four antibodies is apparently identical. Our observations of the synaptic connections of the stained varicosities were incomplete, especially for sublamina $a$. However, in all of our observations in both sublaminae, no difference was noted for any of the antibodies. First, with all four antibodies many of the stained amacrine varicosities in sublamina $b$ form reciprocal synaptic contacts with the rod bipolar at its stereotyped junction, the dyad. Second, only half (approximately) of the reciprocal processes at the dyads are stained by each antibody, and the proportion is not increased by staining with two antibodies at a time. Therefore, the subset of reciprocal amacrine processes stained is probably the same for all four antibodies. Third, all four antibodies stain varicosities presynaptic to alpha ganglion cell dendrites in sublamina $b(\mathrm{ON}$-alpha) and also in sublamina $a$ (OFF-alpha). At these sites of contact, three of the antibodies produce punctate staining of the postsynaptic membrane. The fourth antibody (A257) may also stain the postsynaptic region; however, this antibody produced a general staining of the dendrites that would have obscured the punctate localization of a different determinant. Thus, in this respect as well, all four antibodies may identify the same structure. Finally, all four antibodies stained amacrine varicosities in sublamina $b$ postsynaptic to type $\mathrm{CBb}_{1}$ cone bipolar cells and unstained amacrine varicosities.

\section{Mapping the staining pattern onto the classification of amacrine cell types}

An important question is whether all the stained amacrine synapses belong to a subset of the 22 identified amacrine cell types. Four types of amacrine are known to exchange reciprocal synapses with the rod bipolar axon: A6, A8, A13, and A17. The first three of these types also connect with other cell types, collectively including cone bipolar axons, ganglion cell dendrites, and other amacrine varicosities in sublaminae $a$ and $b$. The A17 amacrine connects only with the rod bipolar (Kolb and Nelson, 1984).

The simplest hypothesis is that all the synaptic varicosities of amacrine types A6, A8, and $\mathrm{A} 13$ share an antigen that binds all four antibodies (Fig. 12). This would account for the stained half of the varicosities reciprocal to the rod bipolar, the unstained portion being attributable to the A17 cell. It would also account for the stained varicosities synaptically associated with

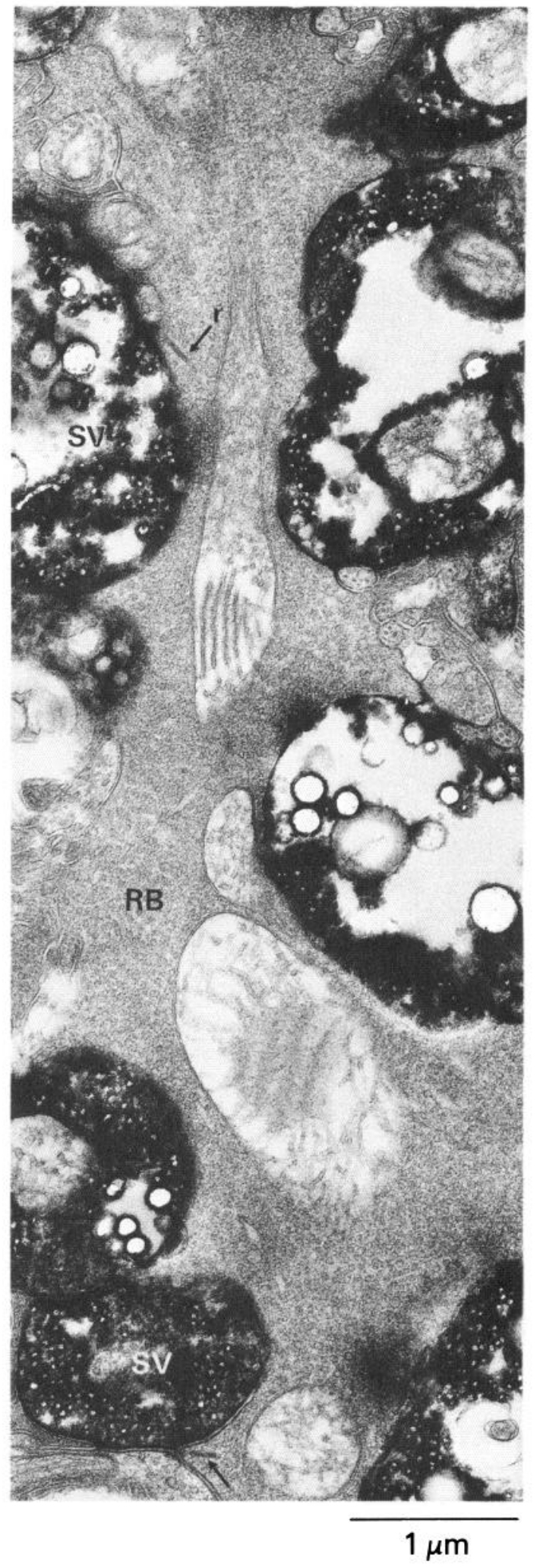

Figure 7. Antibody D334. Unstained rod bipolar axon terminal $(R B)$. Stained amacrine varicosities $(S V)$ postsynaptic at rod bipolar synaptic ribbons (arrows).

structures other than the rod bipolar. If this interpretation is correct, it implies that the A17 amacrine is responsible for about half of all the reciprocal contacts on the rod bipolar. This anatomical feature may be important in understanding the func- 

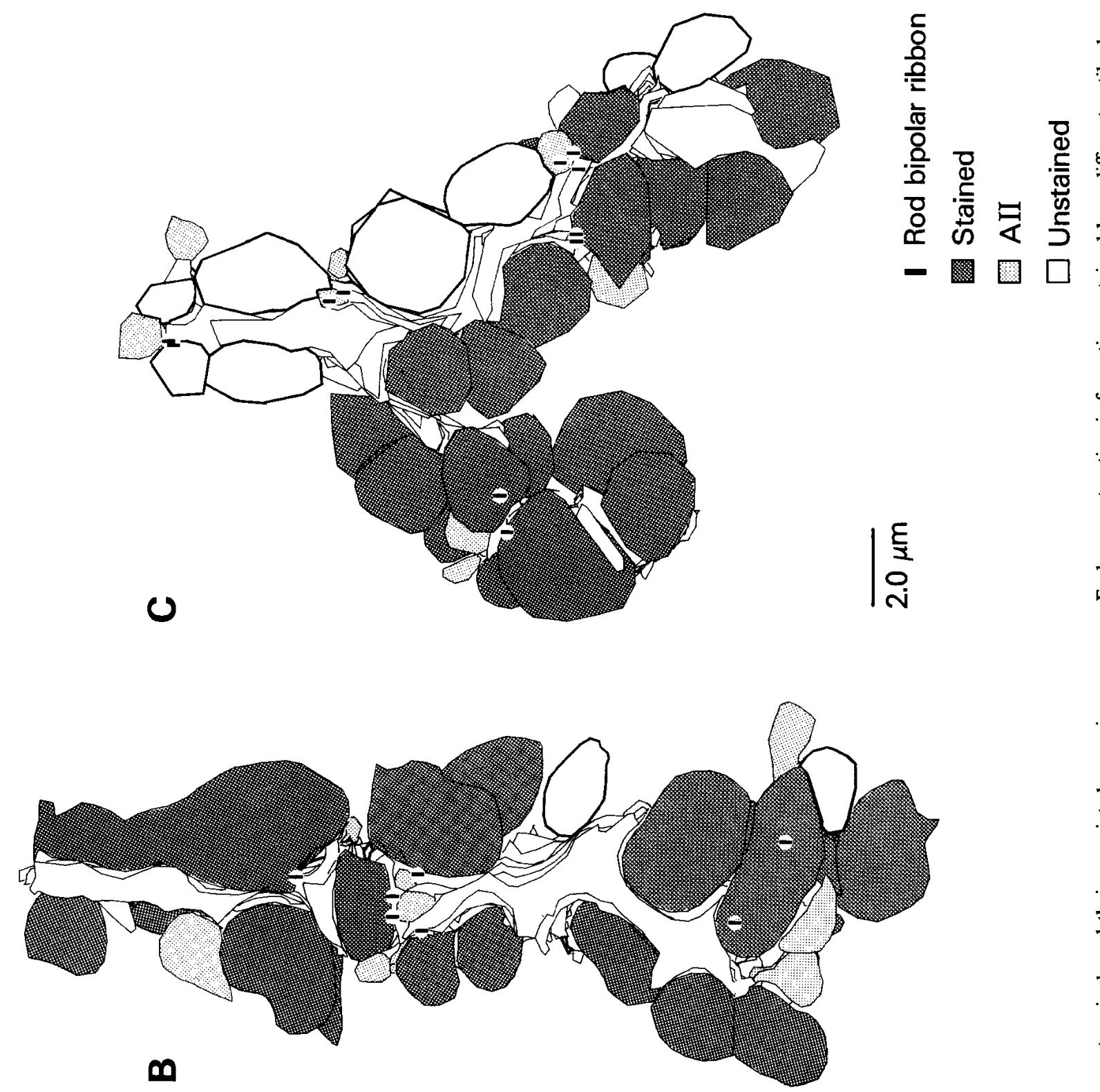

들

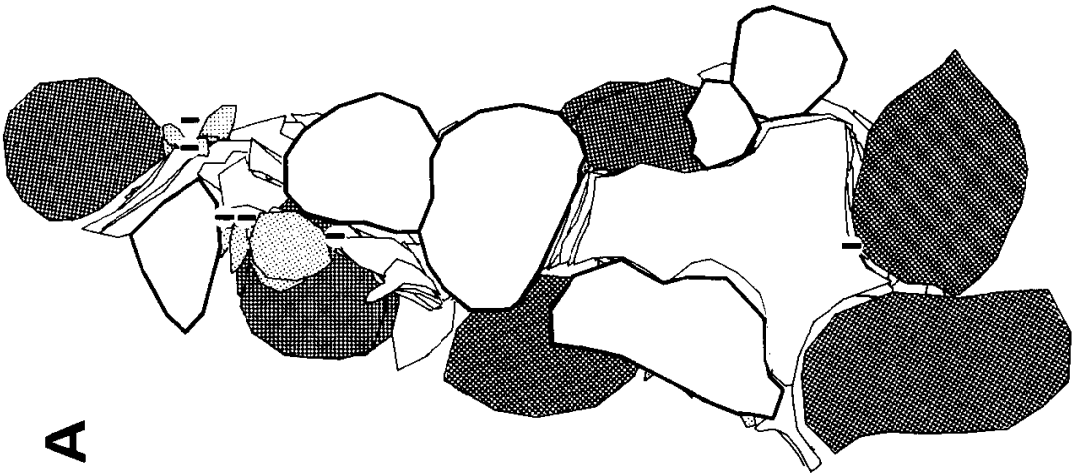




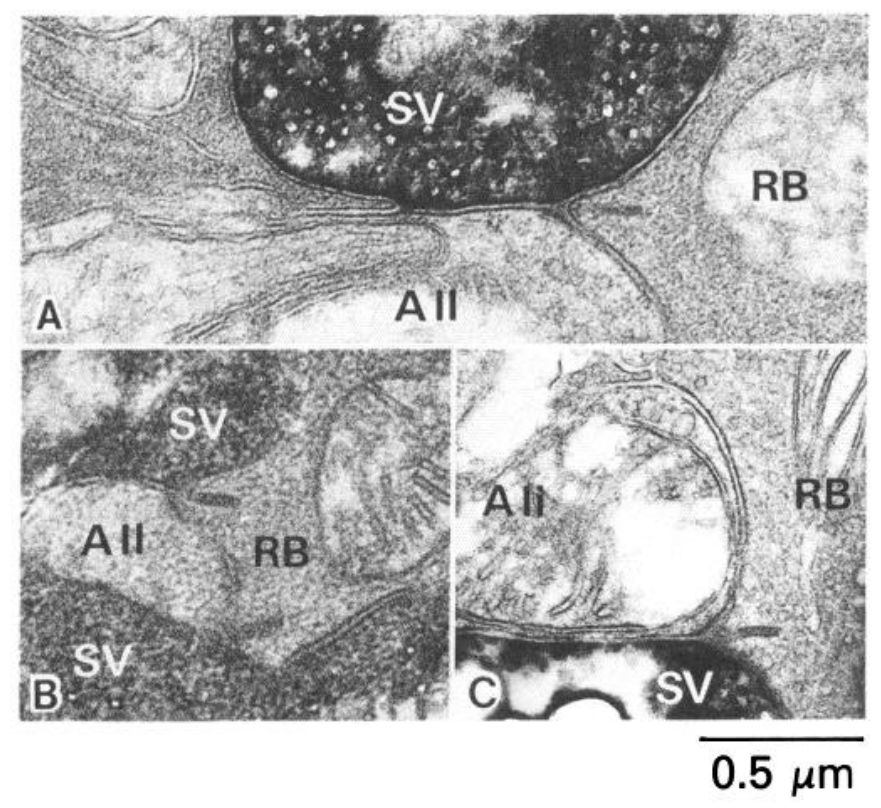

Figure 9. Antibodies D334 (A), A257 (B), and A282 (C). Stained varicosity $(S V)$ postsynaptic to rod bipolar ribbon at dyad. Other member of dyad (AII amacrine) unstained.

tion of the A17 in retinal circuitry (Nelson and Kolb, 1985).

Other hypotheses can be imagined. For example, it could be that A17 accounts for all the stained connections with the rod bipolar and that some as yet unknown set of amacrines accounts for the other stained varicosities. Only further work will tell, but in either case, the subset of amacrines bearing the putative common antigen is likely to be quite restricted.

\section{Molecular bases of the antibody reactivities}

Although the four antibodies described show an exquisite specificity within the inner plexiform layer, these same antibodies react with a variety of retinal cell bodies in the microscopic assay (Fig. 1) and a variety of cat tissues in RIA (Lampson and Sterling, unpublished observations). We suggest that these different activities may reflect recognition of different cross-reactive molecules in different areas and under different assay conditions. It is possible that some of the broader reactivity may represent reactions with cytoskeletal proteins or other abundant molecules with affinity for immunoglobulin. Analysis of the polypeptide chains defined by the different antibodies in structural assays is now in progress. If the explanation offered is correct, it should be possible to raise a second generation of synapse-specific monoclonal antibody with a simplified reaction pattern.

\section{Possible functions of the synapse-associated antigen}

The apparent restriction of an antigen to the synapses of a few amacrine cell types (A6, A8, A13) does not indicate its function, but certain possibilities appear to be eliminated. Since the antigen is present in only a small fraction of all the presynaptic structures, it is unlikely to be associated with any general presynaptic function such as calcium entry. It is also unlikely that the antigen is associated with the neural transmitter metabolism of these cells. The A6, A8, and A13 varicosities thought to bear the antigen are all apparently GABAergic, but so are several other neuron types presynaptic to the rod bipolar (A17, interplexiform cell) that appear to lack the antigen (Freed and Ster-

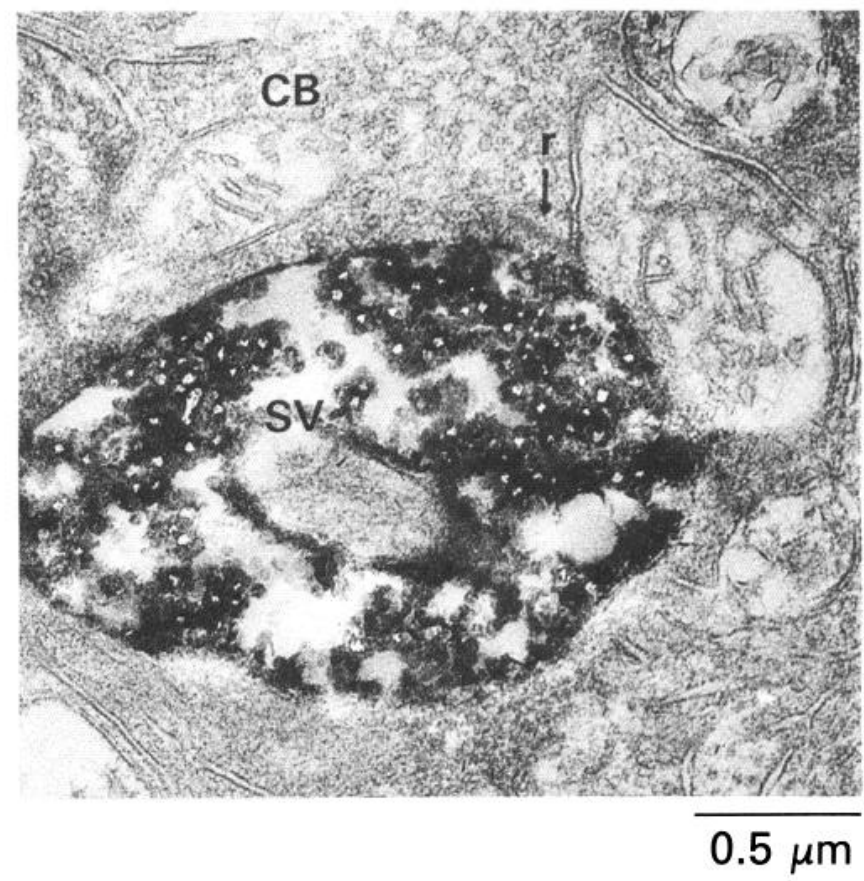

Figure 10. Antibody A282. Stained varicosity ( $S V$ ) postsynaptic to cone bipolar axon terminal $(C B)$ at synaptic ribbon $(r)$ in sublamina $b$ of the IPL.

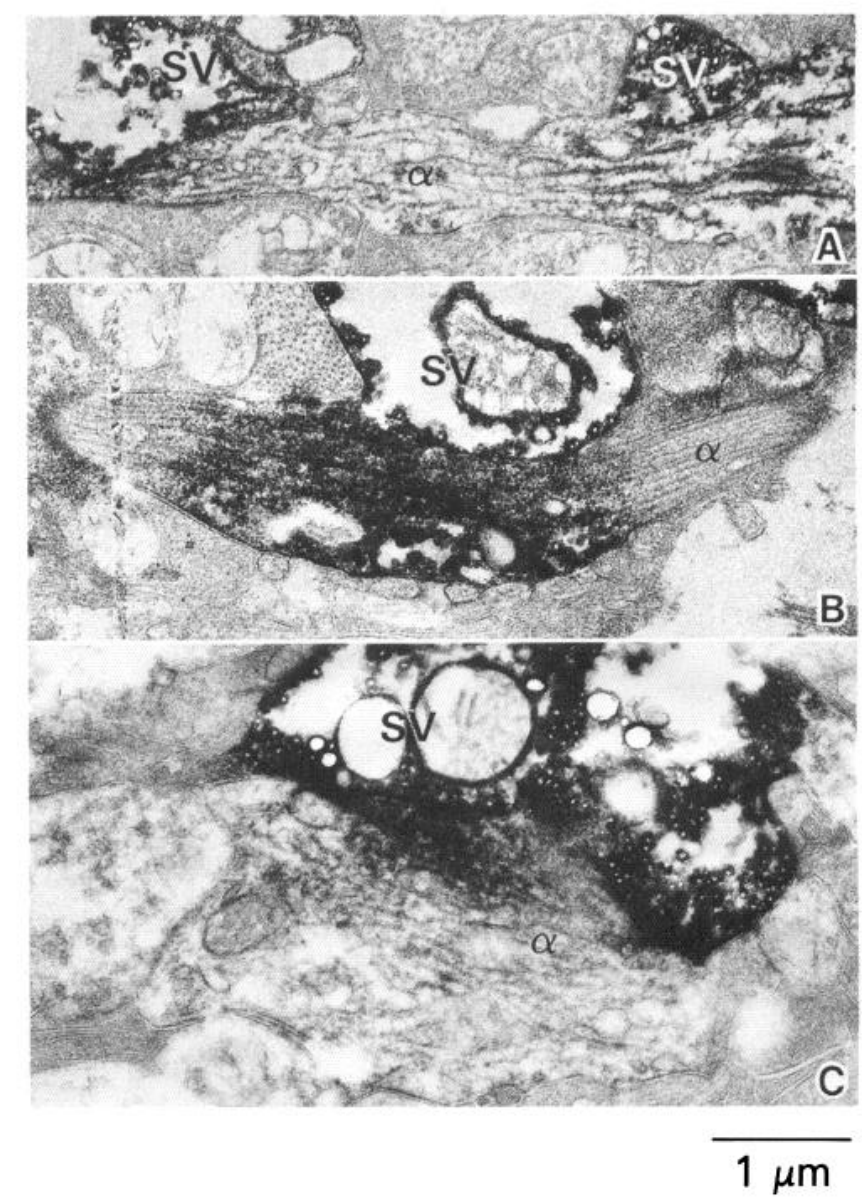

Figure 11. Large dendrites $(\alpha)$ belonging to alpha ganglion cells show staining in cytoplasm and membrane postsynaptic to contact by stained amacrine varicosity: antibody D334 (A), antibody $282(B)$, and antibody A359 (C). 


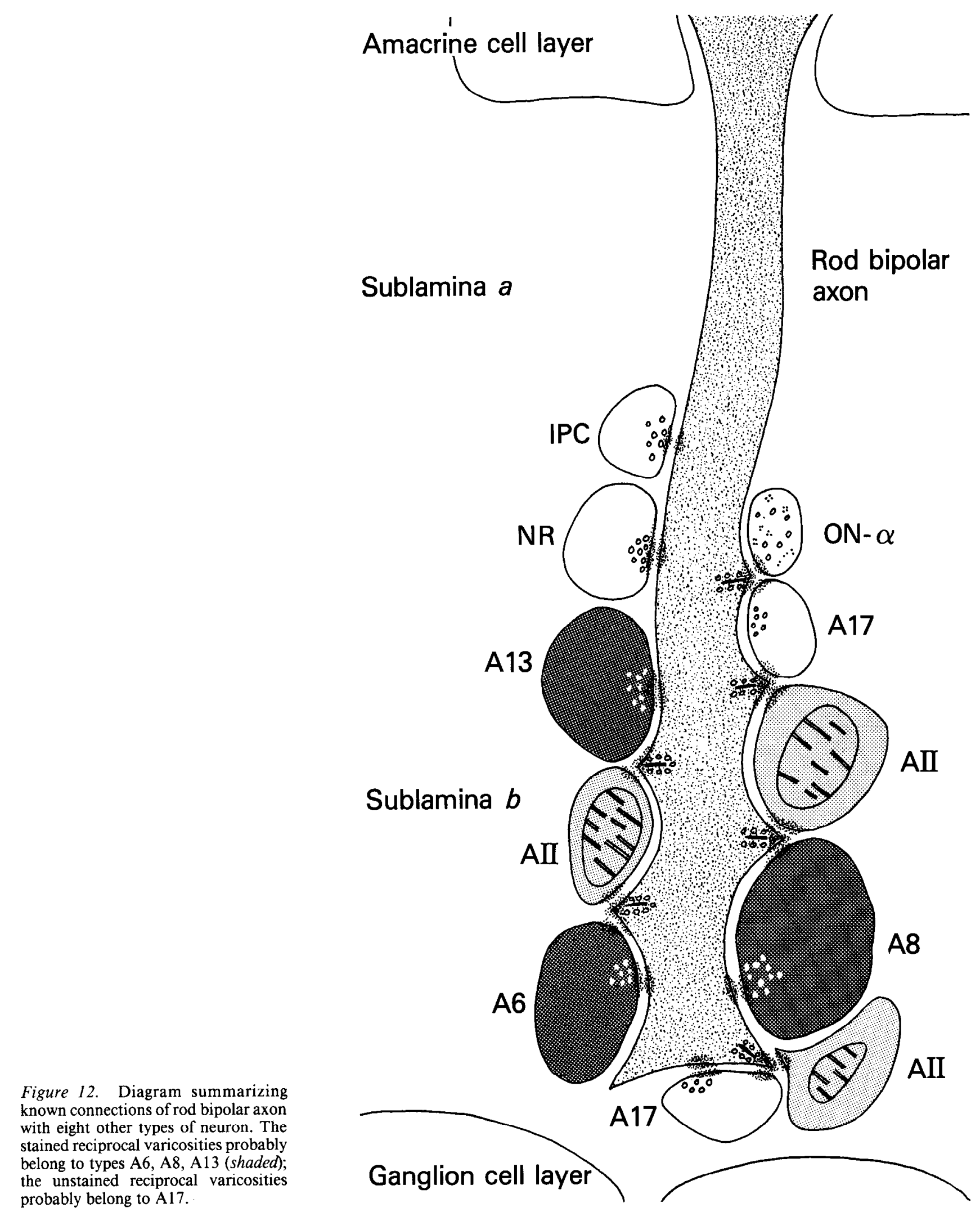

Figure 12. Diagram summarizing known connections of rod bipolar axon wher types of neuron. The probably belong to $\mathrm{A} 17$. ling, 1982; Freed et al., 1983; Pourcho and Goebel, 1983). Thus, it is probably not associated with the uptake or synthesis of GABA. It is also unlikely that the antigen localized here is a neuropeptide. The peptide staining pattern for amacrine cells is well known to display the full arborization of particular cell types and not to be restricted, as in the present case, to the synaptic varicosities (reviewed by Brecha, 1983).

The stained varicosities associated with the rod bipolar axon are postsynaptic, as well as presynaptic. Conceivably, therefore, the antigen could represent a receptor for the rod bipolar's trans- 
mitter. This is unlikely because other types postsynaptic to the rod bipolar (AII, A17) lack the antigen. The possibility of a receptor subtype cannot be completely eliminated, but this would not account for the presence of the antigen in varicosities other than those associated with the rod bipolar. In summary, the highly restricted distribution of the antigen suggests that it is not associated with any known aspect of synaptic transmission or modulation.

It is impressive that the antigen is not localized to the varicosities of a single type of amacrine, but rather to a small subset of the 22 known types, most likely A6, A8, and A13. This is not a random subset, because the three types are strongly related by their shared patterns of connectivity with the rod bipolar axon. To learn whether the antigen is present during the establishment of this connectivity, we recently applied the antibodies to retina of kittens $5-17 \mathrm{~d}$ after birth. This is a period in kitten retina of intense synaptogenesis. We observed by light microscopy that staining is present in the inner plexiform layer at $5 \mathrm{~d}$, mainly in fine processes. By 17 days staining in the inner plexiform layer is hardly distinguishable from that of the adult.

As described above, we are now working to determine the molecular basis of the antibody localizations. This in turn will help us to determine the function of the molecules that the antibodies have defincd. Given the distribution and early developmental appearance of the molecules, a role in establishment or maintenance of synapses is one possibility. Whether this is the case, the molecules do serve as useful markers for a specific set of synapses, and as a demonstration of molecular specificity at this very fine level of neural organization.

\section{References}

Abelson, P., and E. Butz, eds. (1984) Neurosciences. Science 225 : 1253-1370.

Barnstable, C. (1980) Monoclonal antibodies which recognize different cell types in the rat retina. Nature 286: 231-235.

Brecha, N. (1983) Retinal neurotransmitters: Histochemical and biochemical studies. In Chemical Neuroanatomy, P. C. Emson, ed., pp. 85-129, Raven, New York.

Cajal, S. R. (1892) La retina des vertebres. Cellule 9: 119-257. [Engl. trans: Thorpe, S. A., and M. Glickstein (1972) The Structure of the Retina, compiled and trans. S. A. Thorpe, M. Glickstein, Thomas, Springfield, IL.]

Cold Spring Harbor Symposium on Quantitative Biology (1983) $\mathrm{Mo}$ lecular Neurobiology, Vol. 68, Cold Spring Harbor Laboratory, NY.

De Camilli, P., R. Cameron, and P. Greengard (1983) Synapsin 1 (protein 1), a nerve terminal-specific phosphoprotein. 1. Its general distribution in synapses of the central and peripheral nervous system demonstrated by immunofluorescence in frozen and plastic sections. J. Cell Biol. 96: 1337-1354.

Dowling, J. E., and B. B. Boycott (1966) Organization of the primate retina: Electron microscopy. Proc. R. Soc. London [Biol.] 166: 80111.

Dräger, U. C., D. L. Edwards, and C. J. Barnstable (1984) Antibodies against filamentous components in discrete cell types of the mouse retina. J. Neurosci. 4: 2025-2042.

Eldred, W., C. Zucker, H. Karten, and S. Yazulla (1983) Comparison of fixation and penetration enhancement techniques for use in ultrastructural immunocytochemistry. J. Histochem. Cytochem. 31:285292.

Famiglietti, E. V., and H. Kolb (1975) A bistratified amacrine cell and synaptic circuitry in the inner plexiform layer of the retina. Brain Res. 84: 293-300.

Freed, M. A., and P. Sterling (1982) Amacrines reciprocal to the rod bipolar in cat retina are GABA-accumulating. Soc. Neurosci. Abstr. 8: 46.

Freed, M. A., and P. Sterling (1985) Microcircuitry of cone bipolar input to $\mathrm{ON}$-center alpha and beta ganglion cells. Invest. Ophthalmol. Vis. Sci. 26: 194.

Freed, M. A., Y. Nakamura, and P. Sterling (1983) Four types of amacrine in the cat retina that accumulate GABA. J. Comp. Neurol 219: 295-304.

Fujita, S., S. Zipursky, S. Benzer, A. Ferrus, and S. Shotwell (1982)
Monoclonal antibodies against the Drosophila nervous system. Proc. Natl. Acad. Sci. USA 79: 7929-7933.

Hawkes, R., E. Niday, and A. Matus (1982) Monoclonal antibodies identify novel neural antigens. Proc. Natl. Acad. Sci. USA 79: 24102414.

Horwitz, A. F., K. A. Knudsen, C. H. Damsky, C. Decker, C. A. Buck, and N. T. Neff (1984) Adhesion-related integral membrane glycoproteins identified by monoclonal antibodies. In Monoclonal Antibodies and Functional Cell Lines, R. H. Kennett, K. B. Bechtol, and T. J. McKearn, eds., pp. 103-118, Plenum, New York.

Kennett, R. H., and F. Gilbert (1979) Hybrid myelomas producing antibodies against a human neuroblastoma antigen present in fetal brain. Science 203: 1120-1121.

Kennett, R. H., K. A. Denis, A. S. Tung, and N. R. Klinman (1978) Hybrid plasmacytoma production: Fusion with adult spleen cells, monoclonal spleen fragments, neonatal spleen cells and human spleen cells. Curr. Top. Microbiol. Immunol. 81: 77-91.

Kolb, H., and R. Nelson (1984) Neural architecture of the cat retina. In Trends in Retinal Research, Vol. 3, Pergamon, New York.

Kolb, H., R. Nelson, and A. Mariani (1981) Amacrine cells, bipolar cells and ganglion cells of the cat retina: A Golgi study. Vis. Res. 21: $1081-1114$

Lampson, L. A. (1984) Molecular bases of neuronal individuality. In Monoclonal Antibodies and Functional Cell Lines, R. H. Kennett, K. B. Bechtol, and T. J. McKearn, eds., pp. 153-189, Plenum, New York.

Lampson, L. A., and R. Levy (1980) Two populations of Ia-like molecules on a human B cell line. J. Immunol. 125: 293-299.

Lampson, L. A., J. P. Whelan, and C. J. Lawton (1984) Microscopic analysis of monoclonal antibody binding to agarose-embedded cell lines. In Monoclonal Antibodies and Functional Cell Lines, R. H. Kennett, K. B. Bechtol, and T. J. McKearn, eds., pp. 408-412, Plenum, New York.

Lemmon, V., and D. I. Gottlieb (1982) Monoclonal antibodies selective for the inner portion of the chick retina. J. Neurosci. 2: 531-535.

McGuire, B. A., J. K. Stevens, and P. Sterling (1984) Microcircuitry of bipolar cells in cat retina. J. Neurosci. 4: 2920-2938.

McGuire, B. A., J. K. Stevens, and P. Sterling (1986) Microcircuitry of beta ganglion cells in cat retina. J. Neurosci. 6: 907-918.

McKay, R. D. G., and S. J. Hockfield (1982) Monoclonal antibodies distinguish antigenically discrete neuronal types in the vertebrate central nervous system. Proc. Natl. Acad. Sci. USA 79: 6747-6751.

McKay, R. D. G., J. Johansen, and S. J. Hockfield (1984) Monoclonal antibody identifies a 63,000 Dalton antigen found in all central neuronal cell bodies but in only a subset of axons in the leech. J. Comp. Neurol. 226: 448-455.

McLaughlin, B. J., J. F. Wood, K. Saito, R. R. Barber, E. Vaughn, E. Roberts, and J. Y. Wu (1974) The fine structural localization of glutamate decarboxylase in synaptic terminals of rodent cerebellum. Brain Res. 76: 377-391.

Nelson, R., and H. Kolb (1985) A17: A broad field amacrine cell in the rod system of the cat retina. J. Neurophysiol. 54: 592-614.

Oertel, W. H., D. E. Schmcchcl, and E. Mugnaini (1983) Glutamic acid decarboxylase (GAD): Purification, antiserum production, immunocytochemistry. In Current Methods in Cellular Neurobiology, Vol. I, Anatomical Techniques, J. L. Barker and J. McKelvy, eds., pp. 63-110, Wiley, New York.

Okamoto, H., and J. N. Thomson (1985) Monoclonal antibodies which distinguish certain classes of neuronal and supporting cells in the central nervous tissue of the nematode caenorhabditis elegans. J. Neurosci. 5: 643-653.

Ouimet, C., P. Miller, H. Hemmings, Jr., S. Walaas, and P. Greengard (1984) DARPP-32, a dopamine- and adenosine $3^{\prime}: 5^{\prime}$-monophosphate-regulated phosphoprotein enriched in dopamine-innervated brain regions. J. Neurosci. 4: 111-124.

Pourcho, R., and D. J. Goebel (1983) Neuronal subpopulations in cat retina which accumulate the GABA agonist, $\left({ }^{3} \mathrm{H}\right)$ muscimol: A combined Golgi and autoradiographic study. J. Comp. Neurol. 219: 25-35.

Sterling, P. (1983) Microcircuitry of the cat retina. Annu. Rev. Neurosci. 6: 149-185.

Sterling, P., and L. A. Lampson (1983) Monoclonal antibodies mark specific types of amacrine varicosity in cat retina. Soc. Neurosci. Abstr. 9: 803.

Sternberger, L. (1979) Immunocytochemistry, 2nd ed., Wiley, New York.

Sternberger, L., L. Harwell, and N. Sternberger (1982) Neurotypy: Regional individuality in rat brain detected by immunocytochemistry 
with monoclonal antibodies. Proc. Natl. Acad. Sci. USA 79: 13261330.

Stevens, J. K., B. A. McGuire, and P. Sterling (1980) Toward a functional architecture of the retina: Serial reconstruction of adjacent ganglion cells. Science 207: 317-319.

Young, H. Y., and J. E. Dowling (1984) Monoclonal antibodies distinguish subtypes of retinal horizontal cells. Proc. Natl. Acad. Sci. USA 81: 6255-6259.
Zipser, B., and R. McKay (1981) Monoclonal antibodics distinguish identifiable neurons in the leech. Nature 289: 549-554.

Zipursky, S. L., T. R. Venkatesh, and S. Beuzer (1985) From monoclonal antibody to gene for a neuron-specific glycoprotein in Drosophila. Proc. Natl. Acad. Sci. USA 82: 1855-1859. 